\title{
Correlation of Heart Rate and Anthropometric Parameters with Performance Scores Obtained From IAAF Tables in Elite Ethiopian Middle Distance Runners
}

\author{
Hailu Kinfu ${ }^{1}$, Yekoye Abebe ${ }^{2}$, Egidio Beretta $^{3}$, Giuseppe Miserocchi ${ }^{*}, 3$ \\ ${ }^{I}$ College of Medicine, Hawassa University, P.O. Box 1560, Hawassa, Ethiopia \\ ${ }^{2}$ Faculty of Medicine, Addis Ababa University, P.O. Box 1176, Addis Ababa, Ethiopia \\ ${ }^{3}$ Department of Experimental Medicine, University of Milano-Bicocca, Via Cadore 48, Monza, Italy
}

\begin{abstract}
The level of athletic performances is commonly rated with the International Association of Athletics Federations (IAAF) score value. For running events, this scoring system proved to be strongly based on the total power output corresponding to a given performance. The aim of this study was to develop a semi-objective rating system for competitors in $800-1500 \mathrm{~m}$ races based on the correlation between IAAF scores and anthropometric parameters. The study was carried out in top Ethiopian athletes, with IAAF score ranging 976-1113 for men and 1008-1093 for women. Significant regressions with negative slope were found in both sexes by plotting individual IAAF score $v s$ sum of skinfold (biceps, triceps, subscapular, and suprailiac) as well as $v s \mathrm{BMI} / \mathrm{sum}$ of skinfold ratio. We also related the increase in heart rate (HR) to the mechanical power output during an exercise test on a variable inclination treadmill through an exponential regression of the type $\mathrm{Y}=\mathrm{Y} 0+\mathrm{A}^{*} \exp (\mathrm{B} * \mathrm{X})$, where $\mathrm{Y} 0$ represents the asymptotic value of $\mathrm{HR}$ at the highest work load. Significant relationships with negative slope were found by plotting IAAF score $v s$ Y0 in both sexes indicating that a lower cardiac burden at any mechanical load corresponds to a higher athletic fitness.
\end{abstract}

Keywords: IAAF score, skinfold, submaximal heart rate, power output.

\section{INTRODUCTION}

Several reports indicate that African athletes possess specific functional features such as a greater running economy, a higher fractional utilization of oxygen [1] as well as the ability to sustain high-intensity endurance exercise [2]. As far as Ethiopian athletes are concerned, environmental and genetic influences may justify their success in endurance events [3]. Furthermore, in high altitude Ethiopian residents $(3500 \mathrm{~m})$, haemoglobin, erytropoietin and oxygen saturation were found close to sea level control, despite chronic, lifelong hypobaric hypoxia [4].

In this study we aimed at relating the International Association of Athletics Federations (IAAF) score of Ethiopian male and female middle distance runners to their morpho-functional features and cardiac burden derived from a submaximal ergometric running test.

\section{MATERIALS AND METHODOLOGY}

The study was carried on elite middle distance male $(\mathrm{N}=11)$ and female $(\mathrm{N}=10)$ runners belonging to the Ethiopian National team, competing on 800 and $1500 \mathrm{~m}$ races. The study design appropriate for this study was crosssectional. The athletes were selected in the top range by IAAF score. For males, the IAAF score ranged from 976 (corresponding to 1'51'9 for $800 \mathrm{~m}$ and 3'50"06 for $1500 \mathrm{~m}$ ) to 1113 (corresponding to 1 ' 47 '"01 for 800 and 3'39'55 for

\footnotetext{
*Address correspondence to this author at the Department of Experimental Medicine, University of Milano-Bicocca, Via Cadore 48, Monza, Italy; Tel: +39(0)2 64488309; E-mail: giuseppe.miserocchi@unimib.it
}

$1500 \mathrm{~m})$. For females the IAAF score ranged from 1008 (corresponding to 2' $08^{\prime \prime} 48$ for $800 \mathrm{~m}$ and $4{ }^{\prime} 45^{\prime \prime} 85$ on $1500 \mathrm{~m}$ ) to 1093 (corresponding to 2'03" 46 for $800 \mathrm{~m}$ and 4 ' 14 " 40 for $1500 \mathrm{~m}$ ). The mean IAAF score was 1040.9 (coefficient of variation, $\mathrm{CV}=4.1 \%)$ for male and $1050.7(\mathrm{CV}=2.8 \%)$ for females.

Performances were obtained after consulting the official rankings recorded by Ethiopian Athletics Federation. The best performance for each athlete, either on 800 or on $1500 \mathrm{~m}$, was converted into points based on the Scoring Tables of the IAAF [5-7]. These tables allow converting the quality of the performance into a numerical value typically between 0 and 1400, accounting for the run time, the placing as well as the importance of the race. The score is used to produce rankings of performance at various competition levels (international, national, club, school, etc) and to establish the best athlete award in a specific competition.

The study was approved by the ethical committee of Addis Ababa University, Institutional Review Board (IRB) and athletes enrolled signed an informed consent after being informed on the experimental protocol.

The experimental data were collected at the Federal Sport Health Center Laboratory, National Olympic Gymnasium, Addis Ababa University, and Faculty of Medicine Laboratories.

Average age and anthropometric data of the subjects are reported in Table $\mathbf{1}$.

Health status of the subjects was evaluated by a sport physician enquiring for injury or disease precluding the 
enrollment in the ergometric test and in pulmonary function testing.

Table 1. Physical Characteristics of Male and Female Runners

\begin{tabular}{|c|c|c|}
\hline & Males & Females \\
\cline { 2 - 3 } & Mean \pm SD & Mean \pm SD \\
\hline \hline Age (years) & $20.4 \pm 2.5$ & $19.7 \pm 2.9$ \\
\hline Mass $(\mathrm{kg})$ & $62.7 \pm 5$ & $49.25 \pm 4.6$ \\
\hline Height $(\mathrm{cm})$ & $178.2 \pm 5.2$ & $167.08 \pm 5.5$ \\
\hline BMI $\left(\mathrm{kg} / \mathrm{m}^{2}\right)$ & $19.7 \pm 0.9$ & $17.78 \pm 1.4$ \\
\hline
\end{tabular}

\section{Ergometric Test}

Before testing the subjects were familiarized with exercise protocol. The tests were performed on an electronically braked treadmill (Technogym HC 1200, Italy) while subjects were wearing a chest belt sensor (cardiotester) (Technogym, Italy) for heart rate recording. The standard continuous graded exercise test protocol was given according to Astrand Protocol on treadmill. Due to limitation of the maximum velocity of the treadmill, this protocol allowed to increase $\mathrm{VO}_{2}$ by increasing the slope. Uphill running also offers the chance to estimate the net mechanical work (W) done by the athlete to increase the potential energy of the body [8]. The net work is given by $\mathrm{W}=$ weight* $\Delta \mathrm{H}$, where $\Delta \mathrm{H}$ is the vertical distance given by $\Delta \mathrm{H}=\mathrm{D} * \sin \alpha$, where $\mathrm{D}$ is the distance run on the incline and $\alpha$ is the angle between zero level and treadmill inclination.

This analysis provides an estimate of the net average mechanical work to maintain a constant position of the center of mass above the treadmill, neglecting work dissipation due to inefficient biomechanics. Dissipation of energy includes oscillations of the center of gravity in the latero-lateral direction as well as in the vertical direction when the actual vertical displacement exceeds $\Delta \mathrm{H}$.

The subjects were kept $3 \mathrm{~min}$ at $10 \mathrm{~km} / \mathrm{hr}$ and $0 \%$ slope for warming up; next, the speed was increased to $14 \mathrm{~km} / \mathrm{h}$ and kept constant while inclination was increased by $2.5 \%$ every 2 minutes up to $12.5 \%$ slope in men and $10 \%$ slope in females. All male and female athletes could run at the highest slope corresponding to a submaximal exercise level.

Prior to incremental exercise testing, resting heart rate was recorded by ECG (Fukuda Denshi Co. Ltd, Tokyo, Japan). During the test, heart rate was derived from cardiotester chest belt during the last 15 seconds of each work level.

\section{Body fat Composition}

Body Mass Index (BMI) was calculated using standard formula.

A measurement of skin fold thickness was performed at four sites using a Harpenden caliper (British Indicators Ltd., St. Albans, UK), having an accuracy of $0.2 \mathrm{~mm}$. The skinfold site was biceps, triceps, subscapula, and suprailiac. The landmarks were identified and measured according to Wilmore and Behnke [9]. The skinfold site was marked with a surgical marking pen. All skinfolds were taken on the right side of the body, and the same experimenter took a minimum of two measurements at each site in a rotational order. The average of two measurements within $10 \%$ of each other was recorded as the skinfold thickness for that site. Body fat percentages were determined according to Siri equation [10].

\section{Statistical Analysis}

Values are expressed as mean \pm Standard Deviation (SD). To determine if pulmonary function tests, heart rate (HR) and sum of four skinfold thicknesses serve as predictors of running performance, Pearson correlation analysis was performed on those variables based on the athlete's current performance. SPSS software version 12 was used for data analysis. Statistical significance was fixed at the $\mathrm{p}<0.05$ level.

\section{RESULTS}

\section{Skinfold Thickness Measurements}

Average sum of skinfolds values and fat percentage for male and female athletes are summarized in Table $\mathbf{2}$.

Table 2. Descriptive Statistics of Sum of Skinfolds Measurement of the Male and Female Athletes and Fat Percentage

\begin{tabular}{|c|c|c|c|c|}
\hline \multirow{2}{*}{} & \multicolumn{2}{|c|}{ Males } & \multicolumn{2}{c|}{ Females } \\
\cline { 2 - 5 } & Range & Mean \pm SD & Range & Mean \pm SD \\
\hline \hline Sum of skinfolds (mm) & $20-27$ & $23 \pm 2$ & $24-35$ & $27 \pm 4$ \\
\hline $\begin{array}{c}\text { Fat percentage } \\
\text { \% body weight) }\end{array}$ & $8.1-10.5$ & $9.2 \pm 1.3$ & $16.8-20.5$ & $18.2 \pm 1.6$ \\
\hline
\end{tabular}

Table 3 reports the Pearson coefficients indicating significance of the correlation between IAAF scores and sum of skinfold.

Table 3. Correlation Between Sum of Skinfolds and Body Fat vs IAAF Scoring in Male and Female Athletes

\begin{tabular}{|c|c|c|c|}
\hline & & $\begin{array}{l}\text { Sum of } \\
\text { Skinfold }\end{array}$ & $\begin{array}{l}\text { Body Fat } \\
\text { Percentage }\end{array}$ \\
\hline \multicolumn{4}{|l|}{ Females } \\
\hline IAAF scoring & Pearson Correlation & $-0.77 * *$ & $-0.84 *$ \\
\hline \multicolumn{4}{|l|}{ Males } \\
\hline IAAF scoring & Pearson Correlation & $-0.80 * *$ & $-0.63 *$ \\
\hline
\end{tabular}

Fig. (1A) shows that a significant negative linear relationship was found $(\mathrm{P}<0.01)$ in males by plotting individual IAAF scores $v s$ sum of skinfold; Fig. (1B) shows the regression for female athletes, suggesting that IAAF score increases remarkably when sum of skinfold decreases below $30 \mathrm{~mm}$.

Fig. (2A, B) also shows that significant relationships $(\mathrm{P}<0.01)$ were found by plotting IAAF score $v s \mathrm{BMI} /$ sum of skinfold ratio that can be considered an estimate of lean/fat body weight ratio. 

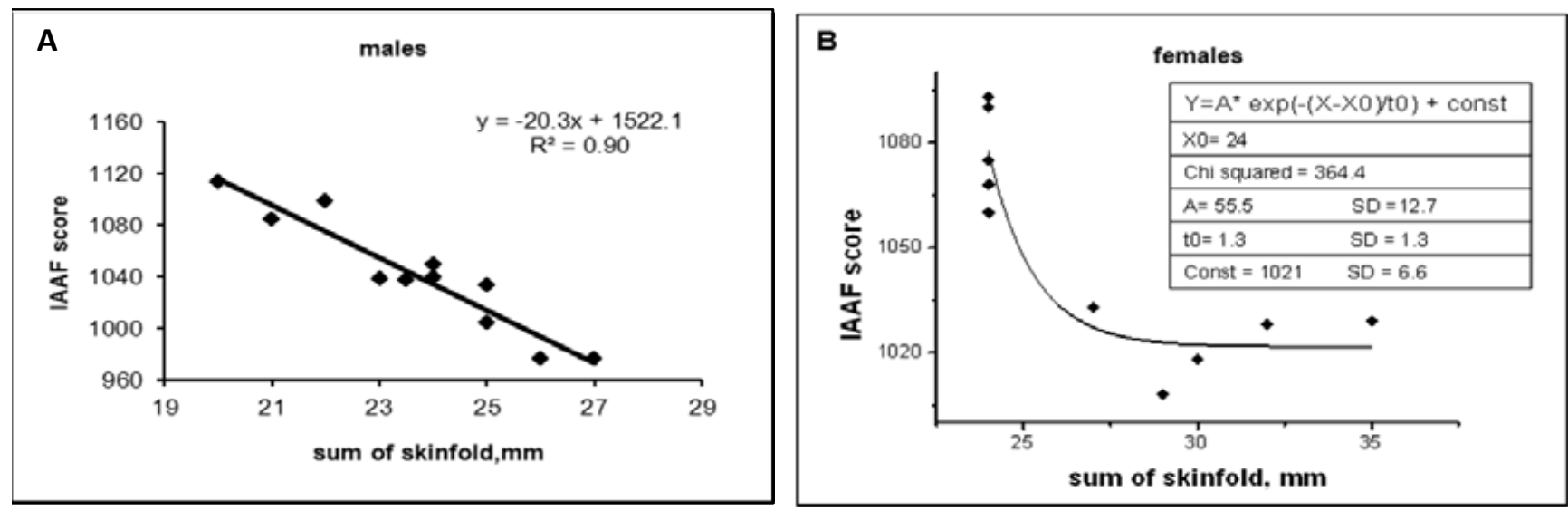

Fig. (1). Individual plots of IAAF score $v s$ the sum of skinfold (expressed in mm) in male (panel $\mathbf{A}, \mathrm{N}=11$ ) and female (panel $\mathbf{B}, \mathrm{N}=10$ ) runners.
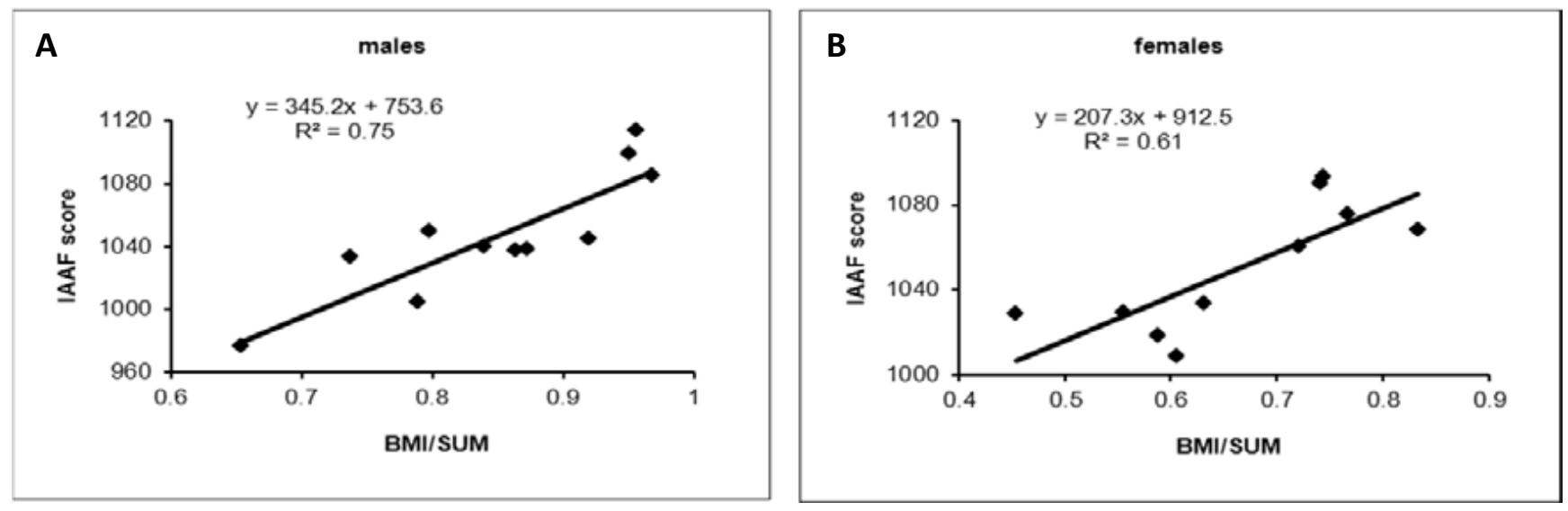

Fig. (2). Individual plots of IAAF score $v s$ the ratio of BMI to sum of skinfold for male (A) and female (B).

\section{Relationships Between Heart Rate and Mechanical Power Output}

Fig. (3A) shows the individual relationships between heart rate (HR) and net mechanical work running uphill for male athletes; data points include resting heart rate values, corresponding to zero mechanical work. The relationships were fitted with an exponential equation of the type: $\mathrm{Y}=\mathrm{Y} 0+\mathrm{A}^{*} \exp \left(\mathrm{B}^{*} \mathrm{X}\right)$. To account for inter-individual differences in morpho-functional features, the heart rate was normalized to BMI/sum of skinfold ratio and plotted in Fig. (3B) as a function of net mechanical work; regression were also fit with an exponential equation. Table 4 reports the equation parameters as well as the regression coefficients corresponding to the individual relationships shown in Fig. $(\mathbf{3 A}, \mathbf{B})$.

Fig. (4A, B) reports for female athletes the same type of relationships shown in Fig. $(\mathbf{3 A}, \mathbf{B})$. Also in this case the same exponential regression model was used and the corresponding parameters and regression coefficients are reported in Table $\mathbf{5}$.

Fig. (5) shows that a significant relationship with negative slope (panel A) was obtained by plotting IAAF score of male athletes $v s$ Y0 (derived from relationships of Fig. 3A) as well as by plotting IAAF score $v s$ Y0 (panel B) (derived from relationships of Fig. 3B).
Fig. (6A, B) report similar graphs for female athletes.

\section{DISCUSSION}

This study represents the first report on top Ethiopian athletes competing in middle distance running. The physiological characteristics and performance level of the Olympic athletes reflect a combination of genetic predisposition and arduous physical training [11]. While it is our belief that these factors represent some of the most important determinants of athletic success, it should be acknowledged that biomechanical, psychological, tactical, nutritional and environmental factors also have the potential to impact upon performance to a greater or lesser extent. Traditionally the level of performance is expressed as IAAF score [5] that was validated by a mathematical model based on theoretical foundation of the physiological principle relating the running performance to total power output $[6,7]$.

A variety of physiological variables have been found to be of importance for the performance level in middledistance running events. The majority of research concerning physiological parameters in middle-distance running dealt primarily with well-trained males whose performances were however quite heterogeneous based on their coefficient of variation $>5 \%$ [12]. This paper reports data on a selected group of athletes that are relatively homogeneous in terms of 
performance because the coefficient of variation of the IAAF score was $<5 \%$.
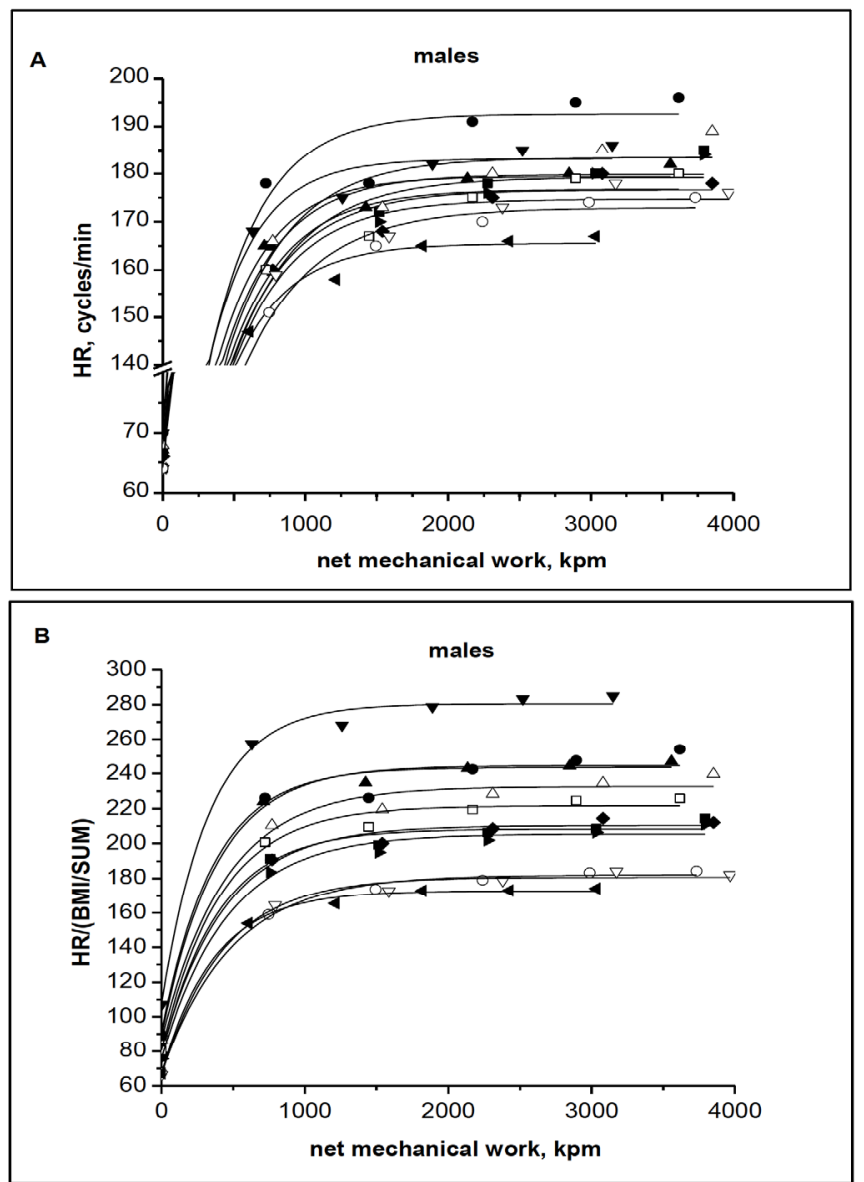

Fig. (3). A: plot of heart rate (HR) vs net mechanical work running uphill for male athletes. B: plot of HR/(BMI/sum of skin fold) $v s$ mechanical work. Data points include resting heart rate values, corresponding to zero mechanical work. These relationships were fitted by an exponential function of the type: $\mathrm{Y}=\mathrm{Y} 0+\mathrm{A}^{*} \exp \left(\mathrm{B}^{*} \mathrm{X}\right)$.

\section{Considerations on Skinfold Data}

In the present study, a sum of four skinfolds and body fat percentage have been found to be associated with 800 and $1500 \mathrm{~m}$ running performance. The sum of skinfolds of these athletes appears significantly lower than that reported for runners having worse performances [13], although skinfold data should be taken with reservation due to differences in technique, equipment and site location.

It is important to point out that the majority of studies regarding association between percent fat and sum of skinfolds with running performance were based on heterogeneous samples. Hartung and Squires [14] found a significant correlation between percent fat and marathon race time in low level athletes, (average best time 3 hours 26 min. $54 \mathrm{~s})$. Ready [15] established that body fat in 10 top-class middle-distance female runners was significantly correlated with provincial ranking. In a study of sixty male distance runners, classified into three homogeneous groups in accordance with their best performance capabilities in $10 \mathrm{~km}$ races, Bale and his colleagues [16] observed that the best runners showed significantly smaller skinfolds values. Similar study also reported a weak but statistically significant association between percent fat and $10000 \mathrm{~m}$ race time in low athletic level female runners (average best time $38 \mathrm{~min} .26 .7 \mathrm{~s}, \mathrm{CV}=6.8 \%, \mathrm{r}=0.33$ ) [17]. In top class athletes, Kenney and Hodgson [18] observed no significant associations between percent fat and $3000 \mathrm{~m}$ steeplechase race time (average best time $8 \mathrm{~min} .38 \mathrm{~s}, \mathrm{CV}=1.2 \%$ ) and $5000 \mathrm{~m}$ race time (average best time $14 \mathrm{~min} .05 \mathrm{~s}, \mathrm{CV}=$ $0.6 \%$ ). Clearly, the higher the level of performance, the more difficult is to correlate running performance to percent body fat.

Interestingly, in both sexes, the IAAF score increased with increasing the BMI/sum of skinfold ratio (Fig. $\mathbf{2 A}, \mathbf{B}$ ). Since IAAF score correlates negatively with sum of skinfold (Fig. 1A, B), the positive slope regression with BMI/sum of skinfold is indicative of an increase in fat free mass, likely muscles.

Table 4. Parameters and Regression Coefficients of the Exponential Fitting $Y=Y 0+A * \exp (B * X)$ Shown in Fig. (3A, B), Referring to Male Athletes. For Each Subject the Corresponding IAAF Score is Reported

\begin{tabular}{|c|c|c|c|c|c|c|c|c|c|}
\hline \multirow{2}{*}{ Subject } & \multirow{2}{*}{ IAAF } & \multicolumn{3}{|c|}{ HR vs Mechanical Work } & \multicolumn{3}{|c|}{ HR/(BMI/SUM) vs Mechanical Work } \\
\cline { 3 - 10 } & & $\mathbf{Y}_{\mathbf{0}}$ & $\mathbf{A}$ & $\mathbf{B}$ & $\mathbf{R}^{\mathbf{2}}$ & $\mathbf{Y}_{\mathbf{0}}$ & \multicolumn{2}{|c|}{ A } & \multicolumn{2}{|c|}{$\mathbf{R}^{\mathbf{2}}$} \\
\hline \hline 1 & 1037 & 179,8 & $-112,7$ & $-0,002$ & 0,99 & 208,3 & $-130,5$ & $-0,002$ & 0,99 \\
\hline 2 & 1033 & 179,3 & $-112,3$ & $-0,002$ & 0,99 & 243,4 & $-152,4$ & $-0,002$ & 0,99 \\
\hline 3 & 976 & 186,1 & $-113,0$ & $-0,003$ & 0,99 & 280,4 & $-173,0$ & $-0,003$ & 0,99 \\
\hline 4 & 1039 & 176,6 & $-110,4$ & $-0,002$ & 0,99 & 210,3 & $-131,5$ & $-0,002$ & 0,99 \\
\hline 5 & 976 & 192,6 & $-122,3$ & $-0,002$ & 0,97 & 254,5 & $-155,3$ & $-0,002$ & 0,97 \\
\hline 6 & 1113 & 165,5 & $-101,3$ & $-0,002$ & 0,99 & 172,7 & $-105,6$ & $-0,002$ & 0,99 \\
\hline 7 & 1038 & 179,2 & $-113,0$ & $-0,002$ & 0,99 & 205,5 & $-129,5$ & $-0,002$ & 0,98 \\
\hline 8 & 1049 & 176,7 & $-112,5$ & $-0,002$ & 0,98 & 221,5 & $-141,1$ & $-0,002$ & 0,98 \\
\hline 9 & 1004 & 183,3 & $-115,1$ & $-0,002$ & 0,98 & 232,6 & $-146,0$ & $-0,002$ & 0,98 \\
\hline 10 & 1084 & 174,6 & $-110,5$ & $-0,002$ & 0,99 & 180,5 & $-114,2$ & $-0,002$ & 0,99 \\
\hline 11 & 1098 & 172,9 & $-108,7$ & $-0,002$ & 0,99 & 182,0 & $-114,4$ & $-0,002$ & 0,99 \\
\hline
\end{tabular}



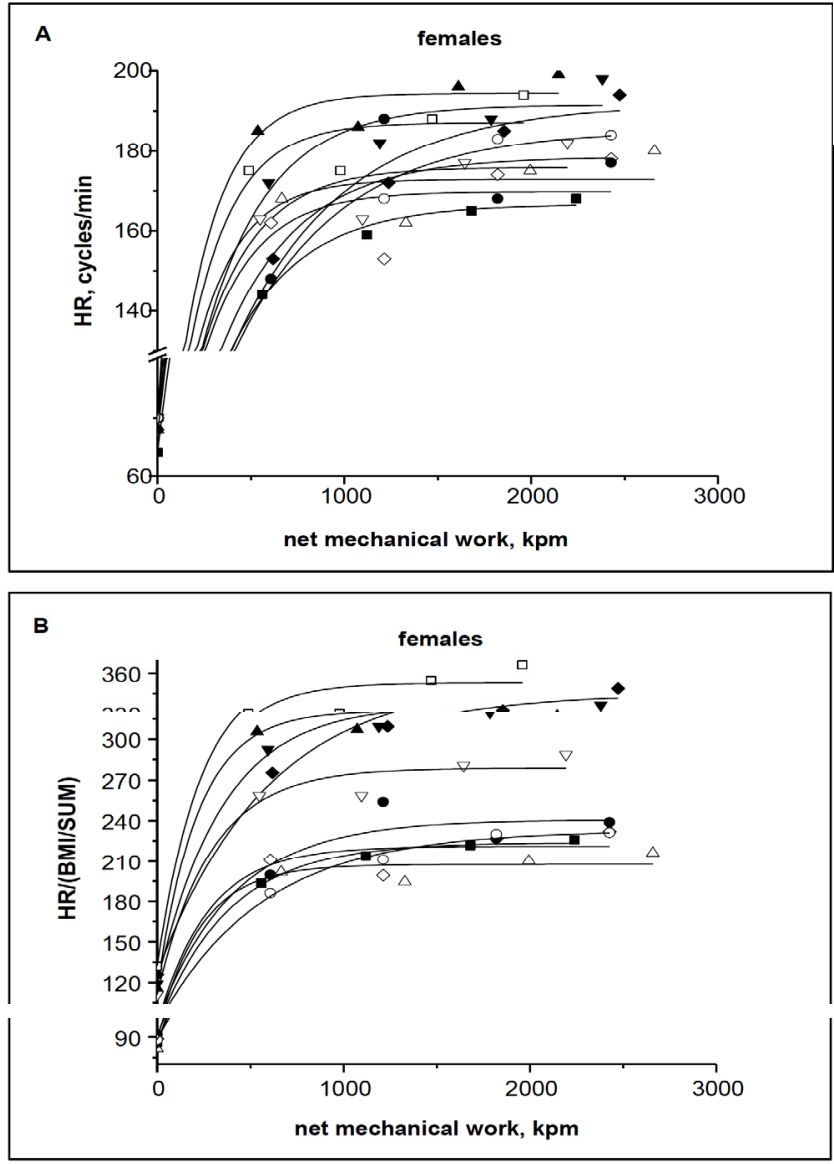

Fig. (4). A: plot of heart rate (HR) vs net mechanical work running uphill for female athletes. B: plot of $\mathrm{HR} /(\mathrm{BMI} /$ sum of skinfold) $v s$ mechanical work. Data points include resting heart rate values, corresponding to zero mechanical work. These relationships were fitted by an exponential function of the type: $Y=Y 0+A^{*} \exp \left(B^{*} X\right)$.

\section{Heart Rate and Energy Yield}

Despite the possible effect of some non-physiological variables on $\mathrm{HR}$ and the fact that $\mathrm{HR}$ measurement is an indirect estimate of the cardiorespiratory responses, it is an indicator of exercise performance. To our knowledge, only three studies have reported the association between the heart rate measured during an incremental treadmill test and IAAF score [19-21]. Like in the present study, these authors found highly positive correlations between submaximal heart rate and race run time in a homogeneous group of marathon runners [21], in heterogeneous groups of middle distance [20] and long distance runners [19].

The exponential functions referring to male athletes shown in Fig. (3A) basically show an equal rate constant (coefficient B in Table 4) but differ as far as parameter Y0 is concerned, that represents the asymptotic value of heart rate at the highest work load: the higher the value of Y0, the greater is the individual cardiac burden to sustain any given mechanical load. The inter-individual differences in Y0 are increased when heart rate is normalized to the BMI/sum of skinfold ratio (Fig. 3B); therefore, this normalization, accounting for differences in morpho-functional features, highlights the corresponding inter-individual differences in cardiac burden. As shown in Fig. (5), the IAAF is significantly higher the lower the cardiac burden, considering both heart rate (Fig. 5A) or normalized heart rate (Fig. 5B).

For female athletes the rate constant B (see Table 5) displays more variability compared to males, reflecting differences in kinetics of heart rate response on increasing mechanical work (Fig. 4A). Furthermore, normalization of $\mathrm{HR}$ to BMI/sum of skinfold (Fig. 4B) decreases the significance of the regression with mechanical work due to variability of anthropometric parameters (Fig. 1B, 2B).

A significant relationships was found between IAAF and HR (Fig. 6A) while this was not true for IAAF $v s$ normalized HR values (Fig. 6B).

In summary, in male athletes, the normalization of heart rate to $\mathrm{BMI} / \mathrm{sum}$ of skinfold ratio allows to increase the sensitivity to predict the IAAF score: in fact, the interindividual variation in $\mathrm{Y} 0$ is in the range of about 100 units of abscissa (Fig. 5B), about three times more than the range in $\mathrm{Y} 0$ if one considers heart rate only (Fig. 5A). Therefore,

Table 5. Parameters and Regression Coefficients of the Exponential Fitting $Y=Y 0+A * \exp (B * X)$ Shown in Fig. (4A, B), Referring to Female Athletes. For Each Subject the Corresponding IAAF Score is Reported

\begin{tabular}{|c|c|c|c|c|c|c|c|c|c|}
\hline Subject & IAAF & \multicolumn{4}{|c|}{ HR vs Mechanical Work } & \multicolumn{4}{|c|}{ HR/(BMI/SUM) vs Mechanical Work } \\
\hline 2 & 1008 & 194,4 & $-124,3$ & $-0,004$ & 0,98 & 321,0 & $-205,3$ & $-0,004$ & 0,98 \\
\hline 3 & 1018 & 191,6 & $-121,4$ & $-0,002$ & 0,98 & 325,6 & $-206,3$ & $-0,002$ & 0,98 \\
\hline 5 & 1090 & 178,5 & $-111,0$ & $-0,002$ & 0,92 & 240,9 & $-149,8$ & $-0,002$ & 0,92 \\
\hline 6 & 1028 & 187,1 & $-117,0$ & $-0,004$ & 0,96 & 353,1 & $-220,7$ & $-0,004$ & 0,96 \\
\hline 7 & 1068 & 172,8 & $-104,8$ & $-0,004$ & 0,96 & 207,5 & $-125,8$ & $-0,004$ & 0,96 \\
\hline 8 & 1033 & 180,8 & $-105,6$ & $-0,003$ & 0,96 & 278,8 & $-167,5$ & $-0,003$ & 0,96 \\
\hline
\end{tabular}




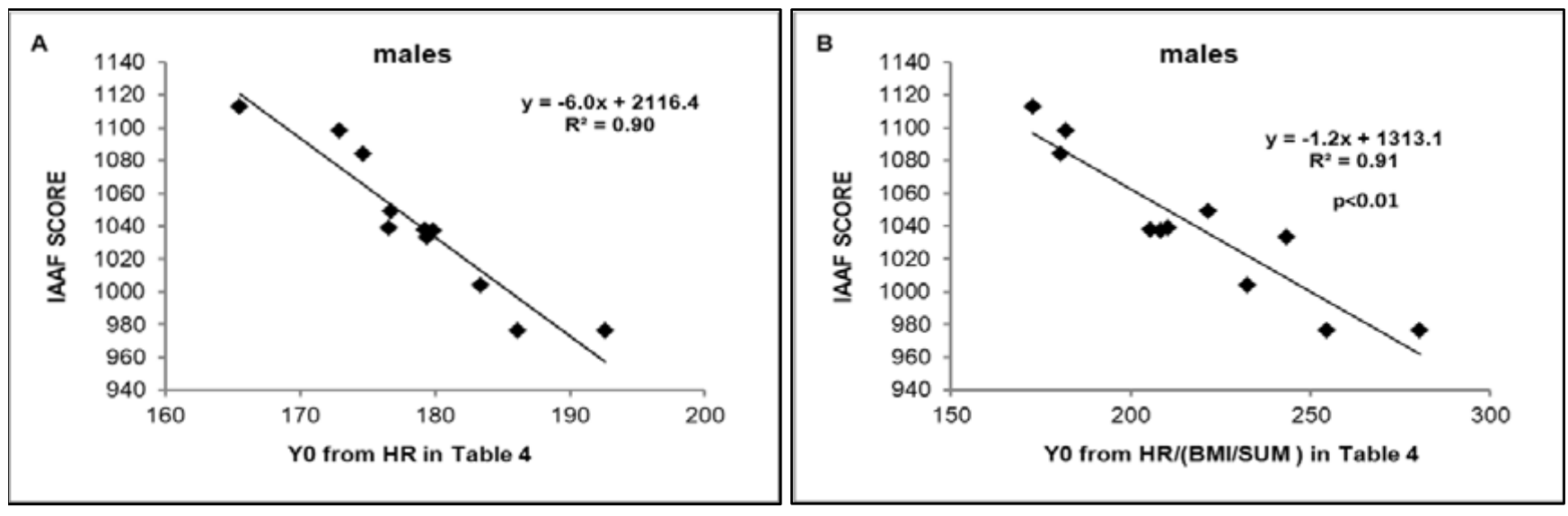

Fig. (5). A: negative correlation between IAAF score in male athletes' $v s$ coefficient Y0 derived from regressions presented in Fig. (3A). B: negative correlation between IAAF score in male athletes' vs coefficient Y0 derived from regressions presented in Fig. (3B).
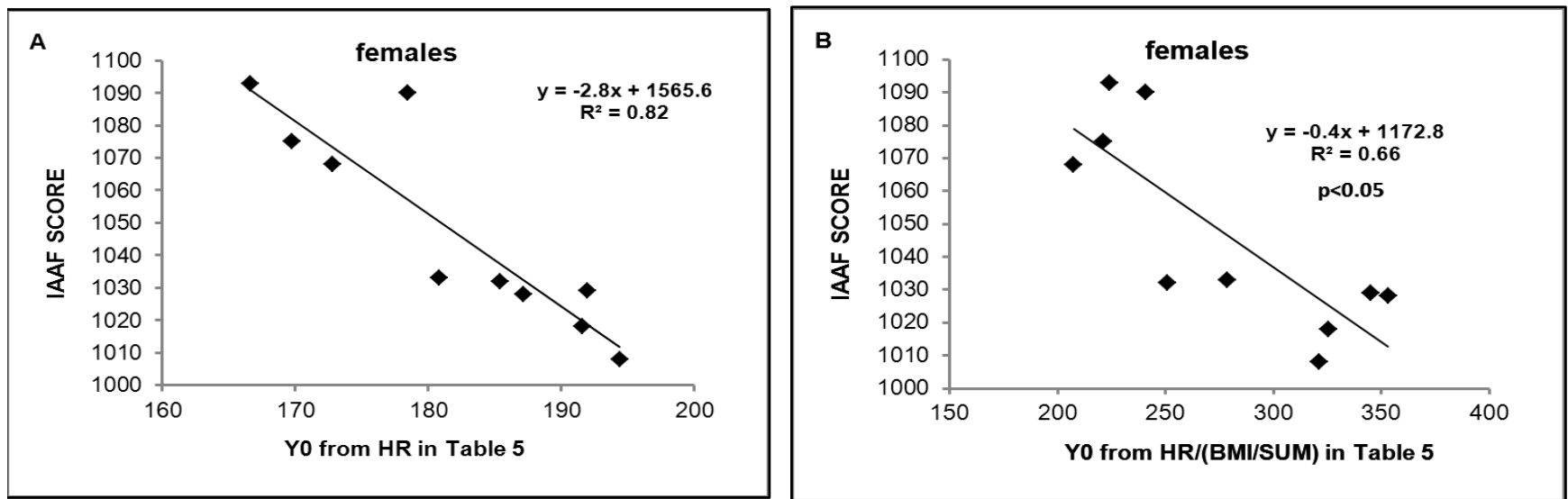

Fig. (6). A: negative correlation between IAAF score in female athletes' vs coefficient Y0 derived from regressions presented in Fig. (4A). B: negative correlation between IAAF score in female athletes' $v s$ coefficient Y0 derived from regressions presented in Fig. (4B).

increasing the relevance of the "cardiac burden" by normalization to anthropometric features appears of interest considering that the cardiac output is an important factor limiting maximum oxygen uptake [22]. A lower submaximal heart rate can be associated with the higher Left Ventricular Diameter (LVD) as previously found in top class runners [21].

We believe that this analysis may represent a useful tool for a functional evaluation of the athletic fitness when no equipment is available to allow the subject to reach his maximum oxygen uptake.

\section{CONFLICT OF INTEREST}

The Authors declare to have no conflicts of interest.

\section{REFERENCES}

[1] Weston AR, Ziphelele M, Myburgh KH. Running economy of African and Caucasian distance runners. Med Sci Sport Exer 2000; 32: $1130-4$.

[2] Weston AR, Karamizrak O, Smith A, Noakes TD, Myburgh KH. African runners exhibit greater fatigue resistance, lower lactate accumulation, and higher oxidative enzyme activity. J Appl Physiol 1999; 86(3): 915-23.

[3] Scott RA, Georgiades E, Wilson RH, Goodwin WH, Wolde B, Pitsiladis YP. Demographic characteristics of elite Ethiopian endurance runners. Med Sci Sport Exer 2003; 35(10): 1727-32.
[4] Beall CM, Decker MJ, Brittenham GM, Kushner I, Gebremedhin A, Strohl KP. An Ethiopian pattern of human adaptation to highaltitude hypoxia. Proc Natl Acad Sci USA 2002; 99 (26): 17215-8.

[5] Available from: www.iaaf.org/Results/Rankings/how.html

[6] Grammaticos B. The physical basis of scoring athletic performance. New Stud Athletics 2007; 22: 47-53.

[7] Purdy JG. Computer generated track and field scoring tables: II Theoretical foundation and development of a model. Med Sci Sports 1975; 7(2): 111-5.

[8] Roberts TJ, Belliveau RA. Sources of mechanical power for uphill running in humans. J Exp Biol 2005; 208: 1963-70.

[9] Wilmore JH, Behnke AR. An anthropometric estimation of body density and lean body weight in young men. J Appl Physiol 1969; 27: 25-31.

[10] Siri WE. Gross Composition of the Body. In: Advances in Biological and Medical Physics New York: Academic Press 1956; vol. IV.

[11] Karlsson J, Saltin B. Diet, muscle glycogen and endurance performance. J Appl Physiol 1971; 31: 203-6.

[12] Legaz-Arrese A, Munguia-Izquierdo D, Nuviala AN, ServetoGalindo O, Urdiales DM, Masia JR. Average $\mathrm{VO}_{2}$ max as a function of running performances on different distances. Sci Sport 2007; 22: 43-9.

[13] Bosch AN, Goslin BR, Noakes TD, Dennis SC. Physiological differences between black and white runners during a treadmill marathon. Eur J Appl Physiol Occup Physiol 1990; 61: 68-72.

[14] Hartung GH, Squires WG. Physiological measures and marathon running performance in young and middle-aged males. J Sport Med Phys Fit 1982; 22: 366-70.

[15] Ready AE. Physiological characteristics of male and female middle distance runners. Can J Appl Sport Sci 1984; 9: 70-7. 
[16] Bale P, Bradbury D, Colley E. Anthropometric and training variables related to $10 \mathrm{~km}$ running performance. $\mathrm{Br} J$ Sports Med 1986; 20:170-3.

[17] Tanaka K, Mimura K, Kim HS, et al. Prerequisites in distance running performance of female runners. Ann Physiol Anthropol 1989; 8: 79-87.

[18] Kenney LW, Hodgson JL. Variables predictive of performance in elite middle.-distance runners. Br J Sports Med 1985; 19: 207-9.

[19] Costill DL, Thomason H, Robert E. Fractional Utilization of the aerobic capacity during distance running. Med Sci Sport Exer $1973 ; 5: 248-52$.
[20]

Pate RR, Sparling PB, Wilson GE, Cureton KJ, Miller BJ. Cardiorespiratory and metabolic responses to submaximal and maximal exercise in elite women distance runners. Int J Sports Med 1987; 8: 91-5.

[21] Legaz-Arrese A, González-Carretero M, Lacambra-Blasco I. Adaptation of left ventricular morphology to long-term training in sprint- and endurance-trained elite runners. Eur J Appl Physiol 2006; 96: 740-6.

[22] Warren GL, Cureton KJ. Modeling the effect of alterations in hemoglobin concentration on $\mathrm{VO}_{2} \max$. Med Sci Sport Exer 1989; 21: 526-31.

(c) Kinfu et al.; Licensee Bentham Open.

This is an open access article licensed under the terms of the Creative Commons Attribution Non-Commercial License (http://creativecommons.org/licenses/by-nc/3.0/) which permits unrestricted, non-commercial use, distribution and reproduction in any medium, provided the work is properly cited. 